\title{
PSA screening for prostate cancer
}

\author{
MARCUS V. SADI ${ }^{1 *}$ \\ ${ }^{1}$ Adjunct Professor, Habilitation degree (Livre-docência) in Urology, Escola Paulista de Medicina da Universidade Federal de São Paulo (EPM-Unifesp). Head of the Urologic Oncology Sector at EPM-Unifesp. Graduate \\ degrees from Harvard Medical School and The Johns Hopkins School of Medicine. Member of Academia de Medicina de São Paulo, São Paulo, SP, Brazil
}

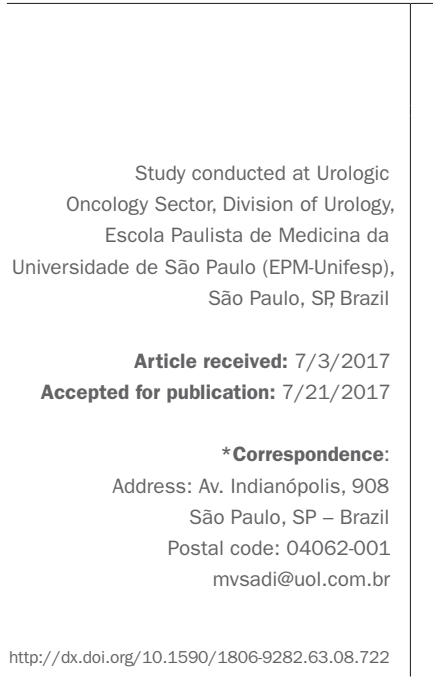

\section{SUMMARY}

Screening of prostate cancer with prostate-specific antigen (PSA) is a highly controversial issue. One part of the controversy is due to the confusion between population screening and early diagnosis, another derives from problems related to the quality of existing screening studies, the results of radical curative treatment for low grade tumors and the complications resulting from treatments that affect the patient's quality of life. Our review aimed to critically analyze the current recommendations for PSA testing, based on new data provided by the re-evaluation of the ongoing studies and the updated USPSTF recommendation statement, and to propose a more rational and selective use of PSA compared with baseline values obtained at an approximate age of 40 to 50 years.

Keywords: PSA, prostate cancer, screening, prostate.
In Brazil, prostate cancer is the most frequent malignant tumor in men, except for non-melanoma skin tumors. More than 62,000 new cases and almost 14,000 deaths are estimated for $2016 / 2017 .{ }^{1}$

Autopsy studies show that up to $60 \%$ of men over the age of 70 may have prostate cancer. However, only a small proportion of these tumors are clinically significant. These tumors of indolent clinical behavior are known as latent cancer, and their diagnosis should be avoided. ${ }^{2}$

Prostate cancer is classified based on the Gleason grading system, which provides scores for each tumor. Due to the common heterogeneity found in these tumors, two scores are stipulated for the predominant pathological aspect of each case, numbered from 1 to 5 . Therefore, the final grades vary from $2(1+1)$ to $10(5+5)$. The higher the score, the more undifferentiated is the tumor, the greater the chance of metastatic disease, and the worse the patient's prognosis. An international consensus of pathologists in 2004 decided to abolish the use of scores 1 and 2 and denote all low grade tumors as 3 . Thus, the lowest currently possible Gleason score is $6(3+3)$, representing tumors of low histological aggressiveness; Gleason $7(3+4$ or 4+3) of intermediate aggressiveness and Gleason 8-9-10, representing aggressive tumors with a high level of anaplasia. Recently, after an analysis of more than 16,000 patients undergoing radical prostatectomy and monitored for several years, the International Society of Urological
Pathology (ISUP) recommended a new tumor classification, as follows: GS $6(3+3=$ ISUP 1$)$ and $7(3+4=$ ISUP 2$)$ representing tumors of lower aggressiveness, GS $7(4+3=$ ISUP 3) and GS 8 (4+4 = ISUP 4), representing tumors of intermediate risk, and GS 9 and 10 (ISUP 5), representing aggressive tumors. ${ }^{3}$ Usually, the tumors found in the screening programs are ISUP 1 or $2 .{ }^{4}$

Over the past 20 years, since the clinical introduction of prostate-specific antigen (PSA), the incidence of metastatic prostate cancer and mortality from prostate cancer has significantly decreased. Although there is no absolute proof that the use of PSA was responsible for this decrease, in the 1980s, localized prostate tumors represented less than $60 \%$ of the cases and in recent years less than $5 \%$ of patients have initial metastatic presentation. Five-year cancer-specific survival increased from $69 \%$ in the 1970 s to more than $95 \%$ nowadays, coinciding with the widespread use of this examination. ${ }^{5}$

An ideal screening program should focus on diseases with high clinical impact on public health; screen the population with a long life expectancy; be able to identify asymptomatic disease at a treatable stage during its natural course; have a high-accuracy, non-invasive, easy-to-apply, low-cost diagnostic tests that does not detect latent tumors; have a treatment capable of modifying the natural history of the disease, reducing mortality without worsening quality of life. 
By not fulfilling all these criteria, the screening of prostate cancer with PSA is a controversial topic. One part of the controversy is due to the confusion between population screening and early diagnosis, another derives from problems related to the quality of existing studies, the results of radical curative treatment and the complications arising from these treatments that affect patient quality of life, such as urinary incontinence and erectile dysfunction.

There are five studies on population screening of prostate cancer. Two of them, which are now old, were performed in Quebec in Canada and Norrköping in Sweden and presented discordant results. ${ }^{6,7} \mathrm{~A}$ review by the Cochrane Library concluded that these two studies had enormous methodological limitations, preventing any appropriate conclusions. ${ }^{8}$ Three other more recent studies presented a better level of evidence. ${ }^{9-11}$

The European Prostate Cancer Screening Trial (ERSPC) randomized a population of 162,243 men between 55 and 69 years for PSA screening $(\mathrm{n}=81,816)$ or control without PSA ( $n=99,184)$. Several centers participated in the study, but the protocol was not the same across all centers. Most of them used a PSA value $\geq 3.0 \mathrm{ng} / \mathrm{mL}$ to indicate prostate biopsy. The PSA level was performed, on average, only every four years. After monitoring for 11 years, screening reduced the risk of metastases by $41 \%$ and the chance of death from prostate cancer by $21 \%$ $(\mathrm{p}=0.04)$. Given the total number of patients submitted to biopsy, $76 \%$ had benign tissue, demonstrating a high index of false-positive results. Of the 781 patients that needed to be screened, 27 were diagnosed and treated to prevent tumor-related death. ${ }^{9,10}$

The American Prostate Cancer Screening Trial (PLCO) study randomized 76,693 men aged 55 to 74 years for annual screening with PSA and rectal exam ( $\mathrm{n}=$ 38,343 ) or control group with the "usual urological care," that is, at the discretion of the urologist $(\mathrm{n}=38,350)$. The PSA value used to indicate biopsy was $\geq 4.0 \mathrm{ng} / \mathrm{mL}$. After seven years of monitoring, mortality was similar between the two groups (p, non-significant). ${ }^{11}$ The problem in this study was the control group. Since "usual care" in the USA includes PSA, in this case almost half of the patients in the control group did the test compared to the randomized group. Therefore, it was to be expected that there would be no difference between groups. At the time of publication, this study was interpreted as being a comparative analysis between two types of PSA screening, one more intense than the other. However, a recent reanalysis of the data showed that in fact more than $85 \%$ of the men in the control group had also undergone PSA testing (and not about $40 \%$, as originally described), which explains more clearly the reason why the result of the study was negative.

In a study conducted in Gothemburg, in Sweden, 20,000 men were randomized 1:1 for PSA screening every two years or control without PSA. Their age ranged from 50 to 64 years (median $=56$ years). The PSA value used to indicate the biopsy was between 3.0 and $4.0 \mathrm{ng} / \mathrm{mL}$. After a 14-year follow-up, there was a relative decrease in prostate cancer mortality of $44 \%$. Prostate cancer was diagnosed in $12.7 \%$ of the patients in the screening group and in $8.2 \%$ of those in the control group. In this study, 293 cases needed to be screened and 12 treated for prostate cancer to prevent one tumor-related death. ${ }^{12}$ These figures are similar to those for breast cancer screening.

However, at the end of 2011 the United States Preventive Services Task Force (USPSTF) issued a report opposing the use of PSA in screening for prostate cancer giving equal weight for all studies. This recommendation has received a "D" grade recommendation, meaning that, in the committee's view, existing scientific data demonstrate that there is more harm than good with the use of this test. ${ }^{13}$ The reasons for this recommendation were diverse.

A major problem for prostate cancer screening with PSA is tumor hyper-detection or over-diagnosis, characterized by excessive diagnosis of clinically insignificant tumors. In fact, in the ERSPC study the finding of low risk tumors (PSA $<10 \mathrm{ng} / \mathrm{mL}$ and Gleason score $\leq 6)$ was almost three times higher in the screened group than the control group., ${ }^{910}$

In the randomized PIVOT trial comparing radical prostatectomy versus observation in the PSA era, it was shown that there was no benefit from radical surgery for patients with low-risk tumors, which are precisely the majority of cases found in screening programs. In this study, there was no difference in mortality after 20 years of monitoring for patients with prostate adenocarcinoma with a Gleason score of 6 between those who did and did not undergo surgery. There was only increased survival in the cases of more aggressive tumors. ${ }^{14}$

Prostate biopsy indications have also changed over the years. After the Prostate Cancer Prevention Trial (PCPT) study showed cancer in at least $15 \%$ of patients with PSA $<4 \mathrm{ng} / \mathrm{mL}$, prostate biopsy began to be recommended with lower PSA values of around $2.5 \mathrm{ng} / \mathrm{mL}$, and this has contributed to the progressive finding of clinically insignificant tumors of lower biological aggressiveness. ${ }^{15}$

The interpretation of the role of PSA becomes even more complex when, in addition to this tumor over-diagnosis, we include the lead time bias and the migration of the screening programs in survival analyses, due to their potential to artificially modify the statistics. 
As a counterpoint to the USPSTF recommendations, in 2013, the American Urological Association (AUA) published its recommendations on using PSA for the early detection of prostate cancer. The panel of urologists recommended PSA screening every 1 to 2 years for men aged 55 to 69 years after a decision shared between the doctor and the patient about the risks and benefits of the test. The text further states that, except for men with risk factors for prostate cancer, routine use of PSA is not recommended for other age groups or if life expectancy is less than $10-15$ years. ${ }^{16}$

It is reasonable to accept that universal screening of the male population, regardless of age and family history, may not be the best approach, but on the other hand there are many methodological flaws in the published studies that have not been correctly interpreted. In addition, one important neglected point in the studies concerns the criteria used to measure the benefit of screening, which is usually only cancer-specific survival. The chance of decreased metastases, quality of life or other benefits that may result from an earlier diagnosis of the disease were not used as a primary parameter in any of the studies.

Vickers et al. demonstrated that PSA levels around 45 years in patients with no family risk factors could provide data on the chance of developing aggressive prostate cancer and risk of death from the tumor in the coming decades. In 21,277 men living in Malmö in Sweden and monitored since 1984 , the authors identified that $44 \%$ of deaths from prostate cancer occurred in patients whose PSA value was above the $10^{\text {th }}$ population percentile. When the baseline PSA values were below the population median according to the different age ranges - namely: up to 42 years: $\leq 0.6 \mathrm{ng} / \mathrm{mL}$; up to 50 years: $\leq 0.7 \mathrm{ng} / \mathrm{mL}$ and up to 55 years: $\leq 0.9 \mathrm{ng} / \mathrm{mL}$-, the chance of death from prostate cancer in 25 years was estimated at $0.1,0.5$ and $0.8 \%$, respectively. These authors suggest that only three PSA measurements, the first performed at around 45 years, the second at the beginning of the fifth decade of life, and the third at 60 years may be sufficient for a safe risk assessment for half of the population. ${ }^{17}$

More recently, the European ERSPC study, now with almost 14 years of median follow-up, confirmed that prostate cancer mortality in PSA screened patients decreased by $32 \% .^{10}$

Thus, as additional evidence published since 2012 continues to show a progressive reduction in prostate cancer mortality with the use of PSA, the USPSTF just promoted a change in its guidelines in May 2017.18

The new recommendation is now grade "C," suggesting that there is a benefit to the use of PSA but that the test should be used selectively based on the professional judgment and patient preferences, recommendations similar to those proposed by the AUA in 2013.

Priority should be given to a shared decision between the physician and the patient about the risks and benefits of using PSA. The USPSTF concludes that there is a small overall benefit after a decade with the use of PSA, but continues to note that damages may occur during this screening period. However, there is still a major age-related problem in this current recommendation, because studies have predominantly included patients aged 55-70 years. Thus, the new USPSTF will not recommend PSA for men over 70 years nor for those under 55 years, which seems inadequate, given that it does not take into account clinical characteristics nor individual volition. ${ }^{18}$

However, this change in guidance seems to be better than the previous one and also occurred because there was a greater acceptance of active surveillance as a therapeutic form for low risk prostate cancer. The use of this approach was only used in $10 \%$ of low-risk prostate cancer cases between 2005 and 2009, and became higher than $40 \%$ between 2010 and 2013, creating the concept of not necessarily relating the diagnosis of prostate cancer with the intervention (diagnosis ₹ prostatectomy or radiation therapy).

A recent study confirms the validity of this approach. ${ }^{19}$ In the ProctecT trial, 1,643 patients with prostate cancer GS $\leq 6$ (ISUP 1) were randomized 1:1:1 among radical prostatectomy, external radiation therapy or active surveillance. After 10 years of monitoring, there was no difference in mortality from prostate cancer between the groups, which was $1 \%$, suggesting an equivalence of therapeutic results and minimal risk of disease progression in this time interval. There were, however, differences between therapeutic approaches. Patients undergoing active surveillance were twice as likely to develop metastases in 10 years compared to those treated radically. Therefore, a longer monitoring period will be necessary to verify if the increased risk of death among the patients under surveillance is actually due to tumor progression or age-related comorbidities. ${ }^{19}$

The Brazilian Society of Urology maintains its recommendation that men over 50 years should seek a professional for an individualized evaluation. Those with first-degree relatives with prostate cancer should begin at age 45. Screening should be conducted after extensive discussion of the risks and potential benefits. After 75 years, it should be performed only for those with a life expectancy of over 10 years. ${ }^{20}$ 


\section{Resumo}

\section{Rastreamento do câncer de próstata com PSA}

O rastreamento do câncer de próstata com antígeno prostático específico (PSA) é uma questão altamente controversa. Parte da polêmica se deve à confusão entre rastreamento populacional e diagnóstico precoce, e outra parte está ligada a problemas relacionados à qualidade dos estudos de rastreamento recentes, a resultados do tratamento curativo radical para tumores de baixo grau ou em estágio precoce, e a complicações advindas de tratamentos que afetam a qualidade de vida do paciente. Nossa revisão teve como objetivo analisar criticamente as recomendações atuais para o teste de PSA, com base em dados obtidos da reavaliação de estudos em andamento e na recomendação atualizada do USPSTF, e propor o uso mais racional e seletivo do PSA comparado a níveis iniciais obtidos em uma idade aproximada de 40 a 50 anos.

Palavras-chave: PSA, câncer de próstata, rastreamento, próstata.

\section{References}

1. INCA. Tipos de câncer. Próstata [cited 2017 Jul 18]. Available from: http:// www2.inca.gov.br/wps/wcm/connect/tiposdecancer/site/home/prostata.

2. Bell KJ, Del Mar C, Wright G, Dickinson J, Glasziou P. Prevalence of incidental prostate cancer: a systematic review of autopsy studies. Int J Cancer. 2015; 137(7):1749-57.

3. Epstein JI, Egevad L, Amin MB, Delahunt B, Srigley JR, Humphrey PA; Grading Committee. The 2014 International Society of Urological Pathology (ISUP) Consensus Conference on Gleason Grading of Prostatic Carcinoma: definition of grading patterns and proposal for a new grading system. Am J Surg Pathol. 2016; 40(2):244-52.

4. Cooperberg MR, Lubeck DP, Mehta SS, Carroll PR; CaPSURE. Time trends in clinical risk stratification for prostate cancer: implications for outcomes (data from CaPSURE). J Urol. 2003; 170(6 Pt 2):S21-5.
5. Welch HG, Gorski DH, Albertsen PC. Trends in metastatic breast and prostate cancer: Lessons in cancer dynamics. N Engl J Med. 2015; 373(18):1685-7.

6. Labrie F, Candas B, Dupont A, Cusan L, Gomez JL, Suburu RE, et al. Screening decreases prostate cancer death: first analysis of the 1988 Quebec prospective randomized controlled trial. Prostate. 1999; 38(2):83-91.

7. Sandblom G, Varenhorst E, Löfman O, Rosell J, Carlsson P. Clinical consequences of screening for prostate cancer: 15 years follow-up of a randomised controlled trial in Sweden. Eur Urol. 2004; 46(6):717-23.

8. Ilic D, O'Connor D, Green S, Wilt T. Screening for prostate cancer: a Cochrane systematic review. Cancer Causes Control. 2007; 18(3):279-85

9. Schröder FH, Hugosson J, Roobol MJ, Tammela TL, Ciatto S, Nelen V, et al.; ERSPC Investigators. Prostate-cancer mortality at 11 years of followup. N Engl J Med. 2012; 366(11):981-90.

10. Roobol MJ, Kranse R, Bangma CH, van Leenders AG, Blijenberg BG, van Schaik RH, et al.; ERSPC Rotterdam Study Group. Screening for prostate cancer: results of the Rotterdam section of the European randomized study of screening for prostate cancer. Eur Urol. 2013; 64(4):530-9.

11. Andriole GL, Crawford ED, Grubb RL 3rd, Buys SS, Chia D, Church TR, et al.; PLCO Project Team. Mortality results from a randomized prostatecancer screening trial. N Engl J Med. 2009; 360(13):1310-9.

12. Hugosson J, Carlsson S, Aus G, Bergdahl S, Khatami A, Lodding P, et al Mortality results from the Göteborg randomised population-based prostatecancer screening trial. Lancet Oncol. 2010; 11(8):725-32.

13. Moyer VA; U.S. Preventive Services Task Force. Screening for prostate cancer: U.S. Preventive Services Task Force recommendation statement. Ann Intern Med. 2012; 157(2):120-34.

14. Wilt TJ, Jones KM, Barry MJ, Andriole GL, Culkin D, Wheeler T, Aronson WJ, Brawer MK. Follow-up of prostatectomy versus observation for early prostate cancer. N Engl J Med. 2017; 377(2):132-142.

15. Thompson IM, Pauler DK, Goodman PJ, Tangen CM, Lucia MS, Parnes HL et al. Prevalence of prostate cancer among men with a prostate-specific antigen level < or =4.0 ng per milliliter. N Engl J Med. 2004; 350(22):2239-46.

16. Carter HB, Albertsen PC, Barry MJ, Etzioni R, Freedland SJ, Greene KL, et al. Early detection of prostate cancer: AUA Guideline. J Urol. 2013; 190(2):419-26.

17. Vickers AJ, Ulmert D, Sjoberg DD, Bennette CJ, Björk T, Gerdtsson A, et al. Strategy for detection of prostate cancer based on relation between prostate specific antigen at age 40-55 and long term risk of metastasis: case-control study. BMJ. 2013; 346:f2023.

18. Bibbins-Domingo K, Grossman DC, Curry SJ. The US Preventive Services Task Force 2017 draft recommendation statement on screening for prostate cancer: an invitation to review and comment. JAMA. 2017; 317(19):1949-50.

19. Hamdy FC, Donovan JL, Lane JA, Mason M, Metcalfe C, Holding P, et al.; ProtecT Study Group. 10-year outcomes after monitoring, surgery, or radiotherapy for localized prostate cancer. N Engl J Med. 2016; 375(15):1415-24

20. Sociedade Brasileira de Urologia. NOTA OFICIAL - Rastreamento do Câncer de Próstata. 2016 [cited 2017 Jul 18]. Available from: http://portaldaurologia. org.br/noticias/nota-oficial-rastreamento-do-cancer-de-prostata-2/. 